\title{
ESCUTANDO SILÊNCIOS OU "EU VI A CARA DA MORTE E ELA ESTAVA VIVA"
}

\section{Clovis Carvalho Britto}

A dissertação de mestrado elaborada por Clarissa De Franco no Programa de Pós-Graduação em Ciências da Religião da Pontifícia Universidade Católica de São Paulo, ora convertida em livro, A cara da morte: os sepultadores, o imaginário fúnebre e o universo onírico, oferece possibilidades analíticas que se expandem para além da área das ciências da religião, contribuindo, seguramente, para a investigação da morte e suas nuanças na inspiração de tessituras teórico-metodológicas para as demais disciplinas das Humanidades. É por essa razão que intitulamos a presente resenha com a provocativa frase de Cazuza, parte do refrão da música "Boas Novas". Não apenas por dialogar com o título da obra em análise, mas, sobretudo, por ressaltar quão vivo permanece o tema da morte em nosso imaginário social.

Seja analisando o cemitério como lugar de memória, de produção artística ou de patrimônio cultural, investigando práticas e representações fúnebres, intersecções com as temáticas de gênero, religião e cultura visual, o tema da morte como apropriação social oferece um profícuo campo de investigação. Entre ritos e mitos, seguindo essa tendência, Clarissa De Franco esquadrinha o imaginário que cerca a morte visando compreender sua configuração histórica e psicológica a partir da análise dos sepultadores de cemitérios paulistanos.

Aqui compreendemos o estudo das figurações da morte de acordo com a análise do processo civilizador apresentada por Norbert Elias $\left(2001^{1} ; 1994^{2}\right)$, especialmente quando investiga as relações sociais em torno do envelhecimento e da morte. Se a finitude da vida é inevitável, muitas são as estratégias de encenar a imortalidade. Do mesmo modo, assegura a necessidade de uma desmistificação da morte, encarandoa como uma questão social. É por isso que sublinha a importância da experiência da morte para a compreensão dos padrões variáveis de coerção e comunicação social. Em outras palavras, as ideias de morte e os rituais correspondentes tornam-se um aspecto da socialização.

O que dizer das pirâmides do Egito ou das práticas de inumação nas igrejas promovidas pelas irmandades religiosas? O que dizer do imaginário religioso atrelado 
à crença no porvir? Das comunidades indígenas na Amazônia à basílica de São Pedro em Roma, aos monges tibetanos, a morte ocupa um espaço significativo nas sociedades humanas, mesmo que para a criação de mecanismos para dela se esquecer ou celebrar. A morte e as mudanças comportamentais documentadas por Philippe Ariès ${ }^{3}$ (2003) em sua História da morte no ocidente atestam isso. No curso do processo civilizador, desenvolve-se a medicamentalização da morte, a preocupação com a assepsia dos moribundos e o desenvolvimento de técnicas de manipulação de cadáveres e sepulturas. À medida que surge uma tendência de exclusão da morte em nosso cotidiano, mais ela ganha força. Talvez porque não seja a morte que desperte temor e terror, mas a imagem antecipada que se tem dela. É por isso que a morte vem sendo encarada como uma figura epistemológica ou, em outras palavras, como uma categoria importante para se pensar e produzir conhecimentos.

É oportuno nesse aspecto o trabalho empreendido por Clarissa Franco por oferecer instigantes caminhos por meio da avaliação das heranças históricas e simbólicas e do universo onírico. Investigando como a morte foi imaginada desde a Antiguidade Clássica, passando pela tradição cristã, até os dias de hoje, reconhece o imaginário como um "conector" entre o mundo externo e o mundo interno do indivíduo. Partindo dessa ideia, originalmente cunhada por Gilbert Durand ${ }^{4}$ (1997), a autora selecionou imagens, símbolos, representações e linguagens em torno do imaginário fúnebre, partindo da hipótese de que os sepultadores desenvolveram uma percepção religiosa e ideológica peculiar frente à morte, visto que o tema parece estar colado a esse grupo de profissionais.

A pesquisa foi desenvolvida nos anos de 2006 e 2007 com sepultadores de cinco cemitérios paulistanos (Araçá, Consolação, Lapa, Vila Mariana e Vila Nova Cachoeirinha). Além dos sepultadores, foram entrevistados os administradores desses locais por meio de entrevistas semidirigidas sobre o cotidiano profissional e a relação com o cemitério, com o intuito de estabelecer interconexões entre o mundo psicológico e o meio cultural, além de relatos de sonhos, visando compreender o imaginário dos sepultadores a respeito da morte:

Os sonhos podem comunicar o modo de compreensão da psique acerca de acontecimentos reais da vida desperta. Considera-se também que os sonhos auxiliam na elaboração e ressignificação desses acontecimentos, oferecendo apontamentos para a vida prática. Diante dessas considerações, partiu-se do pressuposto que seriam encontrados nos sonhos dos sepultadores elementos relacionados à morte, à vivência do cemitério e à experiência do além-vida que pudessem auxiliar na compreensão do imaginário a que estamos investigando. Supunha-se, também, que estes elementos pudessem traduzir algumas imagens e simbolismos da morte em nossa sociedade brasileira, estando relacionadas à vivência de nossa religiosidade popular (Franco 2010:10). 
Se as pesquisas sobre a morte não consistem em temática original, cumpre destacarmos quão inovadora é a proposta ao dialogar Psicologia Analítica com História e Antropologia da Religião.

Dividido em quatro capítulos, o texto inicia descortinando imagens e representações da Antiguidade Clássica, buscando avaliar a constituição do imaginário antigo sobre a morte para a reconstrução de uma linha arquetípica de significados simbólicos sobre a mesma. Aqui a morte é entendia como uma "figura", parte do microcosmo social que possibilita recuperar aspectos importantes do universo histórico-social. Para tanto, o trabalho opta por inventariar as representações convencionadas da morte, da pré-história, do mundo egípcio e greco-romano, por conceber tais matrizes como confluenciadoras em nossa cultura e pensamento.

Em seguida, analisa as representações do universo cristão como estratégia para a compreensão do pensamento hegemônico durante séculos no ocidente. Entremeando essas duas matrizes, oferece uma interessante revisão a respeito do dinamismo das interlocuções entre visões indígenas, africanas e portuguesas na formação da cultura brasileira e de sua religiosidade popular, universo no qual se situam os sepultadores entrevistados.

Por fim, o livro investiga o trabalho de campo e os elementos simbólicos nele identificados. Nesse aspecto, sobressai a importância não somente temática do trabalho, mas metodológica. A descrição da pesquisa de campo, do contato com os sepultadores, das dificuldades e das soluções encontradas é, sem dúvida, um convite à criatividade e à vigilância epistemológica nesse e em outros campos investigativos. Até porque falar de morte é falar do tempo, do espaço e do destino - este último, por sua vez, atrelado a diversos instrumentos oraculares, à religião, ao curandeirismo e à medicina, quando se apodera do saber, nos moldes descritos por Michel Foucault ${ }^{5}$ (2008).

As experiências relacionadas ao trabalho com a morte geram um diálogo simbólico e emotivo entre as pessoas e os objetos. O "olhar do outro" possibilita melhor compreender a identidade construída em torno da morte e os informantes expressam valores culturais, morais e religiosos, aproximando-se daquilo que Maria Elízia Borges ${ }^{6}$ (2008) denominou de contra-olhar nas narrativas da estética popular, da memória e do afeto em cemitérios brasileiros.

Com o intuito de compreender esse olhar, Clarissa De Franco desenvolve uma genealogia/arqueologia foucaultiana recuperando algumas das principais influências que, em seu entender, conformaram as representações da morte no imaginário judaicocristão. Investigando recursos verbais e não verbais, a autora analisou marcos, mitos e templos da Antiguidade, a luta pela salvação da alma presente no imaginário cristão da morte, o "Além" cristão medieval, o medo e o juízo final, a lamentação romântica, a morte secularizando-se e a importância dos cemitérios nos séculos XVIII e XIX. Tal procedimento extrapolou a simples contextualização da temática de estudo: "o imaginário cristão é de fundamental importância para a compreensão do imaginário do sepultador brasileiro, em decorrência da significativa presença que a religião 
católica exerce em nosso país (...) constituindo-se como uma das matrizes de pensamento que norteiam o imaginário" (Franco 2010:117). É por essa razão a necessidade de examinar as raízes e os rizomas da religiosidade popular brasileira com suas matrizes, mitos e vivências cotidianas. As interconexões indígena-africanocatólico e as imbricações entre catolicismo oficial e popular estariam no cerne de nossa religiosidade e, mesmo com as alterações contemporâneas na balança de poderes e saberes das religiões, não podemos negligenciar o peso que o catolicismo exerce em nossa cultura e, por isso mesmo, na conformação dos valores, mitos e ritos relacionados ao imaginário fúnebre. Não sem motivos, a matriz religiosa que impera entre os sepultadores entrevistados é a cristã.

No intuito de compreender essa alimentação ritual, a autora, em primeiro momento, promoveu a escolha dos cemitérios de acordo com as possibilidades oferecidas pelo contato com o campo, já que cada cemitério possui uma especificidade, "tanto no contato com a pesquisadora, quanto de elementos que constituem uma dinâmica própria de funcionamento" (Franco 2010:155). Sublinhando como se deu esses contatos, escolheu como objeto os sepultadores dos cemitérios paulistas da Consolação (devido sua importância histórica) e da Vila Nova Cachoeirinha (por sua situação periférica). Além desses, os cemitérios do Araçá, da Lapa e da Vila Mariana foram sugeridos pela Assessoria de Imprensa dos Cemitérios, após consulta a seus administradores. $\mathrm{O}$ intuito foi perceber os contrastes, especialmente entre os cemitérios da Consolação e da Vila Nova Cachoeirinha.

Enquanto no primeiro são enterradas em maior parte pessoas idosas de morte natural, no segundo, a maioria dos enterramentos consiste de jovens assassinados. Além disso, as condições de trabalho e a paisagem dos cemitérios são diametralmente opostas. Nessa altura do trabalho, começamos a perceber a ironia do título do livro ao constatarmos que a morte possui "várias caras", concebidas em virtude com as experiências de cada indivíduo, compartilhadas socialmente e reproduzidas.

A constatação prepara o encaminhamento para o capítulo final em que se analisa a pesquisa de campo propriamente dita, pautada no imaginário do sepultador: seus relatos, causos e sonhos. Em virtude do silêncio em torno da morte, ao longo dos séculos foi sendo fabricada a "tradição" de destinar os mortos ao cuidado de terceiros especialistas e, dentre eles, os sepultadores se tornam personagens importantes na dinâmica apesar de, na maioria das vezes, tornarem-se invisíveis à família do morto, preparados para não demonstrar sentimentos que possam interferir na dor dos parentes e amigos do de cujus: "em suma, uma máquina preparada para 'limpar' a impressão que a morte causa, enterrando seus resquícios" (Franco 2010:173). É esse um dos insights da pesquisa em questão, optar por ouvir os personagens que a sociedade prefere não escutar e, não raramente, passam despercebidos, transformando-se, assim como as mulheres e outros agentes, naquilo que Michelle Perrot ${ }^{7}$ (2005) definiu como os silêncios da história. Foram essas as impressões da pesquisadora durante as entrevistas com os sepultadores: 
Fica explicitada, portanto, a dificuldade do sepultador no momento de atuar em sua profissão, em que é visto não como humano, capaz de sentimentos empáticos com a dor alheia, mas como um robô. No trabalho de campo, claramente pode-se notar um grande esforço entre os sepultadores de não se pensar na morte, de não sentir nada diante da mesma, de não ser tocado por ela, de sequer falar sobre o tema. Para quem lida com a morte mais de perto, o mecanismo de repulsa precisa ser ainda mais eficaz que o da maioria da população. 'Quando a gente sai do cemitério, a gente não pode ficar pensando na morte, se não, não vivemos'. Essa frase, proferida por um sepultador do cemitério do Araçá, ilustra a dificuldade que existe entre esses profissionais de abordar essa temática (Franco 2010:173-174).

A autora não apenas investiga a relação dos sepultadores com sua profissão, como analisa outras instâncias de suas trajetórias com destaque para sua religiosidade. Dos entrevistados, três se designaram católicos, três se declararam evangélicos e seis disseram não possuir nenhuma religião ou com situação religiosa indefinida. Todavia, Clarissa Franco ressalta que mesmo entre os que não definiram a religião, o discurso e o vínculo com a religiosidade cristã permanecem. A pesquisa também analisa as crenças a partir de suas relações com os cemitérios, os causos de assombração e os interstícios entre o sagrado e o profano, mostrando que o cemitério é encarado como um espaço de subjetividades, de memória social e, especialmente, de memória afetiva. Retoma-se portanto a ideia de um espaço sagrado já que se destaca do espaço profano devido à conotação espiritual que a morte envolve no sentido do que Mircea Eliade ${ }^{8}$ (1992) define como hierofania.

Nas falas dos sepultadores observam-se relatos que envolvem gênero, geração, luto, celebração, enfim, uma trama complexa de economia simbólica impulsionada entre lembranças e esquecimentos. Questões que destacam a forte carga emocional suportada pelos sepultadores que “'entram' na intimidade das famílias, partilhando conteúdos marcantes e tornam-se cúmplices de sua dor e experiência" (Franco 2010:208). Como intermezzo para a saudade, o cemitério articula morte e vida. Aprofundando as análises relativas a esse imaginário, Clarissa Franco conclui sua pesquisa destacando a morte simbolizada pelo inconsciente dos sepultadores utilizando-se, para tanto, de alguns sonhos e relatos.

Apesar de permanecerem na ficção, os relatos do universo onírico, assim como a literatura, dialogam com o real. Os relatos dos sonhos constituíram, assim, em elemento de apoio à pesquisa, referência acerca do imaginário em torno da morte. Em suas análises constata-se que, apesar de nas entrevistas os profissionais declararem que com o tempo se acostumaram com essa realidade, os relatos dos sonhos revelam elementos de angústia, medo e desconforto, como se a negação visível fosse lançada ao inconsciente. Nesse sentido, a autora aponta para a parcela de responsabilidade 
dos sepultadores na elaboração dos conteúdos de morte utilizados em sociedade.

Resta-nos dizer que, assim como o título emprestado da música de Cazuza, a leitura do livro nos trouxe boas novas. Ouvir esses indivíduos silenciados e fitar as diversas caras da morte a partir do imaginário são valiosas contribuições do trabalho que, além de problematizador, oferece muitos campos de pesquisa relacionados à temática. Convida-nos, pois, a trilhar seus passos e avançar na companhia de uma figura epistemológica que certamente nos acompanhará até o resto de nossas vidas.

Notas

1 ELIAS, Norbert. (2001), A solidão dos moribundos seguido de envelhecer e morrer. Rio de Janeiro: Jorge Zahar. Zahar.

(1994), O processo civilizador: uma história dos costumes. Rio de Janeiro: Jorge

3 ARIÈS, Philippe. (2003), História da morte no Ocidente: da Idade Média aos nossos dias. Rio de Janeiro: Ediouro.

4 DURAND, Gilbert. (1997), As estruturas antropológicas do imaginário. São Paulo: Martins Fontes.

5 FOUCAULT, Michel. (2008), Arqueologia do saber. Rio de Janeiro: Forense Universitária.

6 BORGES, Maria Elízia. (2008), Olhar e contraolhar: as narrativas da estética popular, da memória e do afeto nas gavetas funerárias no Brasil. ANPAP. Disponível em: http://www.anpap.org.br/anais/ 2008/artigos/044.pdf. Consultado em 30.11.09.

7 PERROT, Michele. (2005), As mulheres ou os silêncios da história. Bauru: EDUSC.

8 ELIADE, Mircea. (1992), O sagrado e o profano: a essência das religiões. São Paulo: Martins Fontes.

Clovis Carvalho Britto (clovisbritto5@hotmail.com)

Doutorando do Programa de Pós-Graduação em Sociologia, Instituto de Ciências Sociais, Universidade de Brasília. 